\title{
ORIGEN DEL CASTILLO Y COTO DE ARANGA, SIGLOS X-XII ${ }^{1}$
}

\author{
THE ORIGIN OF THE CASTLE AND THE \\ JURISDICTION OF ARANGA, X-XII CENTURIES
}

\author{
CARLOS BARROS \\ Universidade de Santiago de Compostela
}

\begin{abstract}
Resumen
La importancia de las fortalezas altomedievales en la constitución de las jurisdicciones feudales, en los alrededores del año 1000, se ilustra en este trabajo que trata del origen del castillo y coto de Aranga (actualmente, municipio de Galicia) de la casa de Traba. El rey Alfonso IX de León y Galicia traspasa, en 1193, la jurisdicción señorial de Aranga al Monasterio de Sobrado, contra la opinión de sus campesinos y vasallos que, en 1168, preferían seguir perteneciendo a los herederos de los condes de Traba y Aranga.
\end{abstract}

\section{Palavras-Chave}

Castillo, coto, señorío, feudalismo, Aranga, Sobrado, Traba, Alta Edad Media, Galicia

\begin{abstract}
The importance of the fortress of the Higth Middle Age in the constitution of the feudal jurisdictions around the year 1000 is illustrated in this work which is the origin of the castle and a lordship of Aranga (now municipality of Galicia) from the family of Traba. Th king Alfonso IX of Leon and Galicia transferred in 1193, the domain jurisdiction from a Aranga to Monastery of Sobrado, against the opinion of their vassals and peasants who, in 1168 , preferring to continue to belong to the heirs of the counts of Traba and Aranga.
\end{abstract}

\section{Keywords}

Castle, jurisdiction, lordship, feudalism, Aranga, Sobrado, Traba, Higth Middle Age, Galicia

${ }^{1}$ Entregado el 14.10.2008 
La tardía integración -a finales del siglo XII- de la jurisdicción de Aranga en el dominio señorial de Sobrado, siglo y medio después de su fundación oficial como monasterio familiar de los Condes de Présaras, tal vez contribuya a explicar la dureza de los usos y costumbres feudales en dicho territorio, abolidos en parte por la sentencia judicial de $1347^{2}$, así como la rebeldía rampante y secular de la gente de Aranga al dominio cisterciense.

El 23 de octubre de 1193, Alfonso IX dona al Monasterio de Sobrado el castillo del "brozo"3 de Aranga con su coto demarcado ("brozum castelli de Aranga cum toto eo quod inter cantos"), con la condición de que no se tornase a reedificar y que nadie perturbase la (nueva) propiedad jurisdiccional del cenobio con sus marcos de piedra ${ }^{4}$. Fernando III, Alfonso X (1255) y Alfonso XI (1345) confirman un privilegio recopilatorio de Alfonso IX de 1226 reafirmando la donación, junto a otras propiedades, al Monasterio de Sobrado del castillo y coto de Aranga, que aparece "in primis locum". El autor en el siglo XVI de un Códice de Sobrado conservado en el Archivo Histórico Nacional resume, e interpreta, el privilegio de 1193 diciendo Alfonso IX diera al Monasterio el "castillo de broço que por çiertas raçones se avia destruydo con los cotos a el anexos, que es lo que agora se llama tierra de Aranga... y esto con condiçion de que el castillo no se Reedifique, porque estos

2 Véase la nota 62.

${ }^{3}$ Se trata de un apelativo circunstancial (véase la nota 9), las referencias más antiguas (hasta la revuelta irmandiña) lo denominan "castillo de Aranga": en 966 (véase la referencia de la nota 17) y circa 995, cuando el obispo iriense Pedro I (Pedro de Mezonzo) restaura el Monasterio de Santa Eulalia de Curtis, ubicando la parroquia "S. Vicentio de Narmaia, quae est juxta Castellum de Aranga" (incluyendo el territorio, por supuesto), Enrique FLÓREZ, España Sagrada, tomo XIX, 1765, p. 387; la presunta inexistencia del concilio lucense de 569, del que se deriva el llamado privilegio del rey Miro de 570 en que delimita el décimo condado de la Iglesia de Lugo de Narla (en concejo actual de Friol) que llega hasta el castillo de Aranga ("perveniens ad castellum aranga"), no le quita interés a la referencia, que es medieval, aun siendo falso el documento, como defendió Enrique Flórez (España Sagrada, tomo IV, 1749, pp. 130-151) frente a Francisco Huerta y Vega (Anales del Reyno de Galicia, 1733, p. 408) y otros historiadores gallegos, como Manuel Murguía que escribió: " El Concilio II de Lugo no corre con gran predicamento entre los eruditos, mas importa poco; nunca podrá negarse que en los primeros tiempos de la reconquista [siglo VIII], aparece ya el obispado de Iria dividido en condados, de tal manera, que no sería difícil señalar los que correspondieron a esta sede [Lugo] y le fueron asignados en el citado concilio [siglo VI]", El foro. Sus orígenes, su historia, sus condiciones, p. $58 \mathrm{n} .1$.

${ }^{4}$ Mauricio CARBAJO, Cronicón manuscrito de Santa María de Sobrado (1775), Biblioteca Xeral da Universidade de Santiago de Compostela, ms. 587, fols. 425-425v.

${ }^{5}$ Idem, fols. 435-437; el Monasterio solicita en Ourense un traslado notarial del privilegio recopilatorio de Alfonso IX, y las confirmaciones de los reyes posteriores hasta 1345; no existen confirmaciones de reyes del dominio de Sobrado sobre la tierra de Aranga que sean posteriores al pleito con los vecinos que pretende resolver la sentencia del juez real de 1347. 
castillos eran cuevas de ladrones en este Reino, lo que esta dentro de estos marcos es la mas estendida jurisdicción que esta casa tiene"6. El coto de Aranga del Monasterio de Sobrado -hoy ayuntamiento de Aranga ${ }^{7}$ - es, pues, la continuación de la jurisdicción feudal del castillo ${ }^{8}$, que les fue concedido a los monjes cistercienses con la condición de que no lo pusieran en pié, dando a entender el Rey que la fortaleza estaba mejor por los suelos, invadida de maleza ${ }^{9}$. Cuando el monje que escribe el códice dice que el castillo destruido por "çiertas raçones" legitima éstas -fundamentalmente la acción de la monarquía- por los supuestos robos que desde él hacían sus propietarios y habitantes seglares ${ }^{10}$. Queda claro, por lo demás, la importancia del nuevo señorío para Sobrado, por mucho que el monje redactor la exagere $^{11}$. Con todo, a pesar de la incorporación de Aranga a Sobrado en la documentación eclesiástica siguen constando Sobrado y Aranga como jurisdicciones distintas, como se puede ver en las confirmaciones papales a la Iglesia de Santia-

\footnotetext{
${ }^{6}$ AHN Cód. 341, fol. 11.

${ }^{7}$ Como tantos concejos gallegos el origen remoto del municipio de Aranga es una fortaleza y su jurisdicción, después coto de Sobrado, al igual que los ayuntamientos de Curtis, Mesía y Sobrado dos
} Monxes.

${ }^{8}$ El castillo de Aranga estaba situado en el lugar de Congostro, en la aldea de Barreiro, a escasos metros de la confluencia de los ríos Mandeo y Cambás, sobre un gran peñascal, fue excavado y estudiado en 1944 y sus hallazgos están en el castillo de San Antón, Fernando CABANAS, Aportaciones para el conocimiento del castillo y el monasterio de Aranga en el apartado de descargas de www.aranga,es; José María LUENGO, "Exploraciones en el castillo de Aranga (La Coruña)", Cuadernos de Estudios Gallegos, Santiago, no 15, 1950, pp. 21-35.

${ }^{9}$ Es lo que significa el sobrenombre de "broço"; "broza' significa todavía hoy "maleza", tanto en castellano como en gallego; Sebastián Cobarruvias define 'brozno' como "tosco, áspero, por desbastar" (Tesoro de la Lengua Castellana [1611], Madrid, 1984, p. 237), derivándolo del latino 'bruscus", siguiendo a Antonio Nebrija que lo traduce por "cosa brozna y áspera al sentido" (Dictonarium latino-hispanicum [1492], Gerona, 1758, p. 49); Joan Corominas, sin embargo, hace venir tanto 'broza' -entendida como "maleza"- como 'brozno' -entendido como "áspero, bronco"- del céltico y otras lenguas prerromanas, con el significado próximo de "brezos" o "frondoso" (Diccionario crítico etimológico castellano e hispánico, vol. 1, Madrid, 1987, pp. 675-677); pensamos que en latin medieval "brozum" pudo tener ambos significados de maleza y aspereza, aplicable al imaginario de un castillo roquero, derruido y de mal recuerdo.

${ }^{10} \mathrm{El}$ autor del códice está influido probablemente por la memoria colectiva, viva a lo largo del siglo XVI, de la revuelta irmandiña de 1467 contra las fortalezas-nidos de malhechores del Reino de Galicia, entre las que se encontraba el castillo de Aranga, que no parece, sin embargo, haber sido derrocado en el siglo XII por los vasallos (véase la nota 63), ya que estos apoyan a su último propietario noble, Pedro Muñiz, contra el monasterio de Sobrado en el pleito de 1168, como veremos más adelante.

${ }^{11} \mathrm{La}$ integración plena de la tierra de Aranga en Sobrado coincide justamente con el periodo de expansión de su dominio, entre 1160 y 1220, María del Carmen PALLARES MÉNDEZ, El monasterio de Sobrado: un ejemplo del protagonismo monástico en la Galicia medieval, La Coruña, 1979, pp. 130 ss. 
go de los años 1199 y 1225, que dicen -como antes de la integración, en 1178 y 1181- "Superaddo et Aranga"12.

El Monasterio de Sobrado siempre ambicionó el control de la cercana tierra de Aranga, por estar en su espacio natural de expansión entre los ríos Tambre, Mandeo y Eume ${ }^{13}$, complementario del territorio (interior) competencia de la Iglesia de Santiago, entre los ríos Ulla y Tambre, en los siglos XI-XII ${ }^{14}$. A partir de su fundación, en 952, por parte de los Condes de Présaras, los monjes y monjas de Sobrado reciben villas y heredades en la jurisdicción vecina de Aranga ${ }^{15}$, pero no controlan al castillo, y por lo tanto el territorio y los tributos de vasallaje ${ }^{16}$. En 966, Sisnando, obispo de Santiago e hijo de los Condes de Présaras, pretende hacer donación del Castillo de Aranga al Monasterio de Sobrado ${ }^{17}$, por lo que Mauricio Carbajo dedujo en el siglo XVIII, en consecuencia, que la fortaleza perteneció al condado heredado de sus padres ${ }^{18}$. Dudamos de ello, es más probable la posesión, en la segunda mitad del siglo X, de la tierra de Aranga -y por lo tanto del castillo- por parte del conde Gutiérrez Rodríguez de Aranga y esposa, padres de Ilduara Gutierrez de Aranga y abuelos de Elvira de Faro, madre de Pedro Froilaz, primer conde de Traba ${ }^{19}$. Otra cosa es que los fundadores de Sobrado, tuvieran otra intención, sobre la pertenencia de esa jurisdicción menor que, posteriormente, asegura su independencia uniéndose al condado de Traba.

${ }^{12}$ Tumbo B de la Catedral de Santiago, María T. GONZÁLEZ, edit., Santiago, 2004, pp. 529, 545, 581, 606; lo mismo, por ejemplo, en un documento de 1163 sobre heredades en "cauto superaddo et de aranga", Tumbo de Sobrado, I, p. 226.

${ }^{13}$ Ermelindo PORTELA, María del Carmen PALLARES, "Santa María de Sobrado. Tiempos y espacios de un monasterio cisterciense (1142-1250)", De Galicia en la Edad Media, Santiago, 1993, pp. 59, 70 .

${ }^{14}$ José BARREIRO SOMOZA, El señorío de la Iglesia de Santiago de Compostela (siglos IX XIII), A Coruña, 1987, p. 111.

15 En 959, Rodrigo, hijo de los Condes de Présaras, y su mujer Elvira, donan a Sobrado, entre varias propiedades, una villa (núcleo de población y explotación agraria) en Aranga, Tumbo de Sobrado, I, p. 30; que, hacia 971, aparece en un inventario de todas la posesiones de los Condes y sus hijos que pasaron a Sobrado, Idem, p. 138; otras donaciones de heredades -y alguna venta- de particulares a favor de Sobrado en "territorio" o "términos" de Aranga tiene lugar en los años 1131, 1162, 1163, 1164, 1166, 1167, 1171, 1172, 1173, 1184, 1189 y 1230 , Tumbo de Sobrado, I, pp. 200-201, 225-227, 249-252, 522; ARG, Códices Libro 565, fols. 258-258 v; todavía en 1279, cambian los monjes de Sobrado bienes por otros en Aranga, AHN, Sección Nobleza, Osuna C. 488 D. 3.

${ }^{16}$ En el pleito de 1347 no presentan documentación anterior a 1193 que probara el señorío de Sobrado sobre Aranga, porque no la tenían.

${ }^{17}$ Mauricio CARBAJO, Cronicón de Sobrado, fol. 481; el cronista esgrime ese dato para concluir que el castillo y el monasterio de Aranga eran cosas diversas, y dice del lugar de Aranga "que dista tres lenguas largas del de Sobrado y es uno de los principales lugares de su jurisdicción".

${ }^{18}$ Idem, fol. $60 \mathrm{v}$.

19 José Luis LÓPEZ SANGIL, La nobleza altomedieval gallega. La familia Froilaz-Traba, Noia, 2002, p. 16 y cuadro genealógico ${ }^{\circ} 3$ en Apéndice. 
Los padres del obispo Sisnando traspasan el condado de Présaras, en 958 ${ }^{20}$, al recién constituido monasterio de Sobrado. Ni en este documento, ni en los anteriores y posteriores de donación de villas, iglesias y jurisdicciones de la familia de Hermenegildo y Paterna a Sobrado, aparecen nombrados el castillo y la tierra de Aranga. Por lo que inferimos que la tentativa de donación de 966, no tuvo efecto. Con todo, ratifica la importancia jurisdiccional que tiene el castillo de Aranga ${ }^{21}$, uno de los primeros en surgir en el arzobispado de Santiago ${ }^{22}$ : sin la posesión del castillo no será posible durante los siglos $\mathrm{X}^{23}$, XI y XII, asegurar ningún poder señorial en el valle de Aranga.

La realidad es que Aranga no se incorpora al coto de Sobrado hasta el privilegio de donación del rey Alfonso IX de $1193^{24}$. Hasta ese momento, este disputado territorio vertebrado por una fortaleza, consta vinculado, por herencia de los condes de Aranga, a la poderosa casa de Traba ${ }^{25}$, cuya jurisdicción tras-támara (más allá del río Tambre) incluía, de manera natural, el castillo de Aranga y su coto, que pasaron seguramente a los Traba, por el matrimonio a principios del siglo XI de Froila Bermúdez con la nieta del conde Gutiérrez Rodríguez de Aranga ${ }^{26}$. Pedro Froilaz, hijo de Froila Bermúdez y fundador de la casa de Traba, trasmitirá la jurisdicción propia del linaje de su madre a sus hijos y nietos, que anexan en sus títulos feudales Aranga a Traba, como si tuviesen la misma importancia, en la segunda mitad del siglo XII, momento en el monasterio de Sobrado, se expande a la vez que reafirma su independencia entrando en la orden del Císter.

El 12 de febrero de 1156, tenemos así a Gonzalo Fernández de Traba, hijo de Fernando Pérez de Traba y nieto predilecto de Pedro Froilaz, ejerciendo ${ }^{27}$ como

${ }^{20}$ Tumbo de Sobrado, I, pp. 125-127; con todo, ni en este documento, ni en los anteriores y posteriores de traspaso de bienes y jurisdicciones de la familia de Hermenegildo y Paterna a Sobrado, aparece nombrada Aranga.

${ }^{21}$ Falta por revalorizar, e investigar, en Galicia el papel de las fortalezas en la formación del feudalismo, algo habitual en el Occidente medieval, Carlos BALIÑAS, Gallegos del año mil, A Coruña, 1998 , p. 265.

${ }^{22}$ Fernando LÓPEZ ALSINA, La ciudad de Santiago de Compostela en la Alta Edad Media (8001150), Santiago, 1988, p. 225. 22).

${ }^{23}$ En 995, la referencia geográfica al territorio de Aranga es, de nuevo, el castillo (véase la nota

${ }^{24}$ Así, en una delimitación de coto de Sobrado sin fechar, pero posterior a 1193, consta el coto de Aranga, supeditado a la fortaleza como en el siglo X: "et Castello de Aranga cum suo mandamento", Tumbo de Sobrado, I, p. 239.

${ }^{25}$ La casa de los Traba tenía como base principal una fortaleza probablemente situada en la parroquia Santa María de Traba, municipio de Coristanco.

26 Véase la nota 19.

${ }^{27}$ Gonzalo Fernández de Traba, actúa desde 1153, en vida de su anciano padre, como heredero del condado de Traba, Idem, p. 132. 
"comes Gundisalvus senior in Trava et Aranga"28. El 14 de abril de 115729, nuestro "comes domnus Gundisalvus dominante Trava et Aranga", es el confirmante principal de una escritura de Sobrado ("in presentiam comitis donni Gundisalvi") en Santa Eulalia de Curtis, feligresía fronteriza con Aranga ${ }^{30}$ y parte del condado de Traba (o Trastamara). El 1 de junio, aparece de nuevo nombrado al final de una donación de particulares a Sobrado como "Comes Gundisaluus senior in Traua et in Aranga" 31 . E igual el 6 de noviembre de 1157, consta entonces como "Comes Gundissaluus dominator in Travaa et in Aranga" 32 , y el 26 de diciembre del mismo año es mencionado de nuevo como "Comes Gundisaluus senior in Traua et in Aranga" ${ }^{33}$. Se trata, normalmente, de escrituras de Sobrado que tienen que ver con Aranga (donde el monasterio reconocía la autoridad condal de los Traba) y suelen nombrar al rey del momento, al conde de la tierra, el arzobispo de Santiago y el obispo de Lugo. Se repite la formula del conde Gonzalo el 29 de enero de $1159^{34}$, pero el 20 de setiembre de 1161 vuelve a aparecer extrañamente el titulo de su padre ("Comes dompnus Fernandus in Traua et in Aranga et in Monteroso" ${ }^{35}$ ) en una rara fórmula que junta las jurisdicciones Traba-Aranga con el condado de Monterroso, que no detentaba su hijo Gonzalo sino su tío Rodrigo Pérez de Traba, el Velloso ${ }^{36}$.

El último documento conocido del conde Gonzalo de Traba y Aranga es del 31 de diciembre de $1164^{37}$. Hacia 1168 la situación jurisdiccional cambia, en el interior de la extensa familia de los Traba: el territorio de Aranga surge de forma independiente, como en el siglo X, bajo el señorío de Pedro Muñiz, llamado Corna ${ }^{38}$,

${ }^{28}$ Tumbo de Sobrado, II, p. 145.

29 Tumbo de Sobrado, I, pp. 189-190.

30 Véase la nota 3.

31 Tumbo de Sobrado, I, pp. 196-197.

32 Idem, p. 429.

33 Idem, p. 292.

34 Idem, p. 291.

${ }^{35}$ Idem, p. 284; Fernando Pérez de Traba muere entre los años 1160 y 1161; el 17 de abril de 1160, el hijo más influyente de Pedro Froilaz, aparece en una donación de su hermano Bermudo a Sobrado como "comes domnus Fernandus senior in Monterroso et in Traba", sin embargo puede estar errada su mención en la donación del 20 de setiembre de 1161 que comentamos, pues meses antes, el 24 de julio de 1161, consta Fernando Pérez como fallecido al aparecer un documento por Sancha González como su viuda, Historia de la Santa A. M. Iglesia de Santiago de Compostela, IV, p. 273; La nobleza altomedieval gallega. La familia Froilaz-Traba, p. 100; Ermelindo PORTELA, María del Carmen PALLARES, "Aristocracia y sistema de parentesco en los siglos centrales de la Edad Media: el grupo de los Traba", De Galicia en la Edad Media, Santiago, 1993, p. 283 n 20.

36 La nobleza altomedieval gallega. La familia Froilaz-Traba, pp. 112-113; aparecen asimismo las dos denominaciones (Traba-Aranga y Monterroso) separadas en el documento citado del 12 de febrero de 1156 (véase la nota 28).

37 Idem, p. 134.

38 Tumbo de Sobrado, I, p. 330. 
hijo de Lupa Pérez de Traba, hermana de los citados condes Fernando y Rodrigo, oportunamente casada con Munio Peláez, conde de Monterroso ${ }^{39}$. Pedro Muñiz es, por tanto, también nieto de Pedro Froilaz, conde de Galicia, ayo de Alfonso VII y partenaire de Gelmírez en la Historia Compostela. Petrus Munionis, desprovisto del condado de Monterroso de su padre (absorbido por la rama principal de los Traba ${ }^{40}$ ), juega, con todo, un papel político-militar en Castilla como veremos más adelante: se tienen noticias suyas, entre 1158 y 1176, como participante de la curia de Fernando II $^{41}$.

Pedro Muñiz ve pronto impugnado su señorío de Aranga por el emergente monasterio cisterciense. En $1168^{42}$ se enfrenta en un pleito sonado al Monasterio de Sobrado por los hombres de la tierra de Aranga, y otras posesiones (iglesias, sobre todo) en el coto de Sobrado, con el apoyo de los campesinos, de un lado, y la protección por el otro del arzobispo de Santiago, Pedro Gundestéiz (1168-1173), "qui in illo tempore erat adversaruis Superaddi pro causa archiepiscopi dommi Martini"43. El pleito fue visto por Fernando II en la ciudad de Lugo, escuchó a unos y otros, y nombró una comisión arbitral de "bonos hominis" de la nobleza (los Suariz), encabezada por el obispo de Lugo, que sentencia a favor de Sobrado y trata, con este documento del 1 de junio de 1168, presionar a señor de Aranga para que la cumpla. Al inicio se dice que tanto el Rey Fernando II como el arzobispo Gundestéiz, tenían asimismo parte en las jurisdicciones en disputa ${ }^{44}$. El autor del Tumbo de Sobrado donde está la noticia del pleito ${ }^{45}$ presenta, en consecuencia, el

${ }^{39}$ La nobleza altomedieval gallega. La familia Froilaz-Traba, pp. 106-108.

40 A partir de Gonzalo Fernández de Traba, muerto entre 1164 y 1168 (pocos años después que su padre Fernando Pérez), nos encontramos con que la línea principal de sucesión de la casa fundada por Pedro Froilaz, que sigue con Gómez González y termina a mediados del siglo XIII con Rodrigo Gómez, sustituye definitivamente la denominación "Traba y Aranga" (cuyo respectivos castillos son recuperados por la monarquía antes de 1200) por "Tratámara y Monterroso", Ermelindo PORTELA, María del Carmen PALLARES, "Aristocracia y sistema de parentesco en los siglos centrales de la Edad Media: el grupo de los Traba”, De Galicia en la Edad Media, Santiago, 1993, pp, 285, 287 n 33, 288 n 34, 290.

${ }^{41}$ La nobleza altomedieval gallega. La familia Froilaz-Traba, p. 107.

42 Tumbo de Sobrado, II, pp. 47-48.

43 En realidad, el arzobispo Martín (1156-1168) con quien se enfrentó fue con el rey Fernando II, que intentó echarlo de la sede compostelana, buscando y obteniendo el primero el apoyo del Monasterio de Sobrado, que después tuvo problemas en el nuevo arzobispo, Pedro Gundestéiz, Historia de la Santa A. M. Iglesia de Santiago de Compostela, IV, pp. 271, 277-282.

${ }^{44}$ Los intereses de la monarquía y el arzobispado en las tierras de Aranga y Sobrado, explican intervenciones posteriores, como el traspaso a la Iglesia de Santiago de la tierra de Sobrado en 1183 (véase la nota 78) y la recuperación del castillo de Aranga y su territorio, antes de 1193.

45 Tumbo de Sobrado, II, p. 47. 
documento que da noticia del pleito como una "karta diuisionis" que hizo el obispo de Lugo, por la autoridad del rey Fernando, entre el Monasterio de Sobrado y Pedro Muñiz y el arzobispo de Santiago. La sentencia presuntamente arbitral viene a ser fruto de una alianza de Sobrado y Lugo contra Pedro Muñiz y Santiago, que tenían la simpatía de los descendientes de los Traba y del propio rey Fernando II.

A falta de escrituras realmente antiguas de posesión de la jurisdicción de Aranga por parte de Sobrado, la Comisión lucense justifica "ab antiquo tempo" la "hereditatem de Condado" en Aranga como "iur et voce" de Sobrado, haciendo mención del privilegio del 8 de abril de 1151 de Alfonso VII, que redactara de acuerdo de los Condes de Traba, Fernando y Bermudo, donde se delimita de forma harto genérica el coto de Sobrado, sin referencias a Aranga ${ }^{46}$. El documento pro Sobrado de la comisión de 1168, deja en evidencia el incumplimiento por parte del señor de Aranga, ya que hasta ese momento, escriben, los "fratres non receperant", las jurisdicciones y bienes en litigio, que Pedro Muñoz tenía que poner "in manu" del obispo de Lugo. Por el contrario, "Petrus Munione tenuisset totam aliam terram populatam et vocem rusticorum cum sua propria directura", de manera libre y tranquila, a pesar de ser de Sobrado (que "esse de voce Superaddi"). El monasterio valora especialmente, dentro de los derechos del señor en Aranga, las prestaciones personales de carpinteros, pedreros y ganaderos (criadores y cuidadores de bueyes, vacas y caballos) ${ }^{47}$. Lo que demuestra el desarrollo económico y social alcanzado por las aldeas de Aranga, antes de la implantación de las granjas cistercienses de Carballotorto y Carballal en el siglo XIII.

Podemos atestiguar la continuidad de Pedro Muñiz como señor de Aranga, mediante otros documentos. El 12 de julio de 1168, un mes y once días después de la emisión del documento "arbitral" a favor de Sobrado, don Pedro aparece mencionado en una escritura del Tumbo de Sobrado como el "Tenente Aranga, Petro Munionis" seguido de "Gomes Gundisssaui senior in Trava et in Faro"48. Lo que quiere decir que el Monasterio asume de facto la contravención del laudo de la comisión de notables del 1 de junio de $1168^{49}$. El 1 de noviembre de 1169, un año

${ }^{46}$ Tumbo de Sobrado, II, pp. 28-29; por este documento, el autor del códice 341 del AHN, se deshace en el fol. 23 en salmos a don Fernando y don Bermudo que "volvieron a reedificar" el monasterio de Sobrado.

${ }^{47}$ Tumbo de Sobrado, II, p. 48.

48 Tumbo de Sobrado, I, p. 220.

49 No siempre queda rastro documental de la no aplicación de una sentencia; nos preguntamos cuántos pleitos ganados en el papel por los grandes señores resultan después frustrados por la resistencia de los campesinos y sus aliados, dando la falsa idea de que "los campesinos siempre pierden". 
después del pleito, constan de nuevo como jurisdicciones separadas, Aranga y Traba: "Gomez Gundisalui dominante en Trastamar [Traba] et in Faro [A Coruña]", por un lado, y "Petrus Munionis in Aranga", por el otro ${ }^{50}$. El 1 de marzo de 1171, en otro documento -también de los Tumbos de Sobrado- se menciona solamente como autoridad local, de manera grandilocuente, al "Princeps ipsius terre Petrus Munionis, qui tenebat Aranga et suus uicarius Froilla Roderici"51.

En 1176, Pedro Muñiz, ya mayor ${ }^{52}$, todavía frecuenta la corte de Fernando II $^{53}$. La simpatía del rey, y más aún la de arzobispo Pedro Gudestéiz, se vio reforzada por la participación de Pedro Muñiz, y su hijo García, en la defensa de Cáceres en 1170, hecho militar que dio lugar a la Orden de Santiago, de la cual nuestro caballero y señor de Aranga fue uno de los caballeros fundadores ${ }^{54}$. Podemos presumir que, en el momento del pleito con Sobrado por la tierra de Aranga, Pedro Muñiz tenía asimismo el sostén del heredero del condado de Traba-Trastamara, Gómez González ${ }^{55}$ que estaba casado con su hija Elvira Pérez ${ }^{56}$. El conde Gómez confirma, en 1183, la cesión de los derechos históricos de encomienda de los Traba sobre la tierra de Sobrado a la Iglesia de Santiago ${ }^{57}$.

La victoria del nieto segundón de Pedro Froilaz de Traba, e hijo del Conde de Monterroso, contra las pretensiones de Sobrado sobre Aranga parece total en lo inmediato, y más allá de sus apoyos políticos (consecuencia del aprovechamiento "desde abajo" de las rivalidades políticas y señoriales), no se comprende al margen de la voluntad de la "multitudine populorum rusticorum" 58 de preferir el dominio laico de los Traba y Monterroso al señorío monacal de Sobrado ${ }^{59}$. El esencial conflicto campesinos / monjes cistercienses que subyace como motor de fondo del pleito Traba / Sobrado de 1168 viene a demostrar el protagonismo como sujeto his-

50 Tumbo de Sobrado, I, p. 191.

51 Idem, p. 218.

52 Su hijo, Fernandus Petri, confirma en 1175, una donación de su hermana, Tarasia Munioni, a Sobrado, Tumbo de Sobrado, II, p. 63.

53 Véase la nota 150.

54 Historia de la Santa A. M. Iglesia de Santiago de Compostela, IV, pp. 298-300; José FERNÁNDEZ LLAMAZARES, Historia compendiada de las cuatro órdenes militares de Santiago, Calatrava, Alcántara y Montesa, 1862, p. 25.

55 Véase la nota 149.

56 La nobleza altomedieval gallega. La familia Froilaz-Traba, p. 159.

57 Véase la nota 187.

58 Tumbo de Sobrado, II, p. 47.

${ }^{59}$ En el reino bajomedieval de Galicia, ocurrirá más bien lo contrario: los campesinos suelen aliarse con los monasterios contra la agresividad depredadora de la nueva nobleza. 
tórico de la comunidad campesina del coto feudal ${ }^{60}$, más allá de la más conocida comunidad de aldea ${ }^{61}$, y el papel de la resistencia campesina, entre 952 y 1193, a la absorción del coto de Aranga por el Monasterio de Sobrado. Queremos decir con esto que la lucha de los campesinos de Aranga contra el dominio de Sobrado en 1347 (que dio a conocer la práctica del derecho de pernada en la granja de Carballotorto $^{62}$ ), tiene precedentes 179 años antes y coadyuva a entender la severidad de las prestaciones feudales de Sobrado en el coto rebelde.

Entre 1171 y 1193 la situación del coto de Aranga en manos de un rama lateral de los Traba se deteriora, el castillo queda abandonado, Alfonso IX lo recobra y cede a Sobrado de manera definitiva ... hasta las nuevas y violentas intromisiones de la nobleza trastamarista de 1369 en adelante. Desde 995 hasta 1193 se produce un juego de poder a tres bandas entre el Monasterio de Sobrado, el condado de Traba y la Iglesia de Santiago, que los vecinos de Aranga aprovechan bien para mantenerse al margen del poder feudal más importante y temido de la zona, a pesar de la dulcificación social que supone racionalización económica del ideal cisterciense. El monasterio de Sobrado no fue capaz de sustraerle la tierra de Aranga y su castillo ${ }^{63}$ a la casa de los Traba a lo largo del siglo XII. Estos disfrutaban, además de su convergencia puntual con los intereses de los campesinos y artesanos de Aranga, del apoyo de los reyes de León, Alfonso VII (1126-1157) y Fernando II (1157-1188), que se habían criado con ellos ${ }^{64}$. Los monjes que subsistían ${ }^{65}$ en el edificio abacial bastante tenían con defenderse de los intentos de los hijos de Pedro

\footnotetext{
${ }^{60}$ El monasterio de Sobrado: un ejemplo del protagonismo monástico en la Galicia medieval, p. 235.

61 La comunidad campesina del coto, que usualmente suma varias aldeas, refleja mejor en sus relaciones exteriores el régimen feudal imperante.

62 Carlos BARROS, "Rito y violación: derecho de pernada en la Baja Edad Media", Historia Social, UNED, Valencia, $\mathrm{n}^{\circ}$ 16, primavera-verano 1993, pp. 4-5 (se puede consultar en www.hdebate.com/cbarros/spanish/pernada castellano.htm).

${ }^{63}$ El castillo parece estar, en el siglo XII, más dedicado a la protección del señor laico y los vasallos de Aranga frente a otros señores, que a la opresión de los campesinos del coto; durante el siglo XIII y gran parte del siglo XIV permanece derruido, siendo sustituido como centro del poder feudal por la granja de Carballotorto, hasta su reedificación por los nuevos señores (los Andrade y/o los Ulloa) a finales del siglo XIV o principios del siglo XV.

64 Al final de su reinado, en 1183, Fernando II convence al conde de Traba, Gómez González, para ceder el patronazgo de Sobrado al arzobispo de Santiago (véase la nota 78); y será su hijo Alfonso IX (1188-1230) quien pase, en 1193 menguada la casa de Traba, Aranga a Sobrado.

${ }^{65} \mathrm{La}$ crisis de monasterio benedictino no se supera hasta finales del siglo XII, sobre su franca decadencia en la primera mitad del siglo XII, véase El monasterio de Sobrado: un ejemplo del protagonismo monástico en la Galicia medieval, pp. 109 n 25, 112.
} 
Froilaz, condes de Galicia, de sustituir a la extinguida casa de Présaras ${ }^{66}$ en el control vía encomienda del otrora pujante monasterio. Por lo que finalmente fue la Iglesia de Santiago quien protegió la autonomía del monasterio cisterciense, cuando el propio declive y fragmentación de los Traba ${ }^{67}$, hizo posible la neutralización del castillo y la integración de Aranga en el coto de Sobrado.

En 1118, la reina Urraca y su hijo Alfonso VII para agradecer sus servicios a Pedro Froilaz, ayo del rey y primer Conde de Traba, entregan, en forma de encomienda $^{68}$, el Monasterio de Sobrado a sus hijos, Fernando y Bermudo Pérez de Traba, con el argumento autocrítico de que, un siglo antes, Fernando I había usurpado con violencia a los abuelos maternos de los hermanos Traba: condes Sigeredo Aloitez y Adosinda Arias ${ }^{69}$. El patronazgo de los Traba resulta ratificado, en 1135, por un Alfonso VII ya adulto que confirma la donación a los hermanos Traba del monasterio de Sobrado $^{70}$. En 1142, Fernando y Bermudo Pérez de Traba, aceptando los nuevos tiempos, y sus propios fracasos ${ }^{71}$, entregan formalmente el Monasterio (animados por el rey Alfonso) a la orden francesa del Císter ${ }^{72}$. Inicia así la abadía de Sobrado su ascenso económico y social como señorío independiente $^{73}$. Se suceden ahora, paradójicamente, las donaciones a los nuevos monjes (franceses) de heredades de la propia familia de los $\operatorname{Traba}^{74}, \mathrm{y}$ pronto -hacia 1160, cuando muere su hermano Fernando ${ }^{75}$ - ingresa a edad avanzada Bermudo Pérez de Traba como simple monje en Sobrado ${ }^{76}$. En 1151, el emperador Alfonso VII ofi-

66 Idem, pp. 110, 223-224.

${ }^{67}$ Ibidem.

${ }^{68}$ El sistema de encomienda de monasterios se inicia en el siglo XII, suponía el pago de un canon o determinados servicios al señor laico por la protección recibida, dando lugar a grandes abusos en los siglos XIV-XV, José GARCÍA ORO, "Los señoríos monásticos gallegos en la Baja Edad Media", Compostellanum, Santiago de Compostela, vol. XIV, 1969, pp. 563-568.

${ }^{69}$ Carta de donación real, fechada el 29 de julio de 1118, del Monasterio de Sobrado a los Traba que enmienda la acción del abuelo de doña Urraca "quod prefuit auus uestro Segeredo Aluiti et de uxore sua Adosinda Arie uiolenter sine omni directo”, en Tumbo de Sobrado, II, pp. 23-24.

70 Tumbo de Sobrado, II, pp. 24-25.

71 Al sustituir a los condes de Presaras, propietarios y fundadores en el siglo X del Monasterio, el linaje de los Traba y sus antecesores oscilan, en realidad, durante los siglos XI y XII, entre la continuidad del trato a Sobrado como un monasterio familiar y la simple encomienda, más adecuada en los siglos XII-XIII a la autonomía de las nuevas órdenes religiosas.

72 Tumbo de Sobrado, II, pp. 27-28.

${ }^{73} \mathrm{El}$ auge del Sobrado cisterciense va en paralelo con la decadencia de los Traba, El monasterio de Sobrado: un ejemplo del protagonismo monástico en la Galicia medieval, pp. 223-224

74 Idem, p. 224.

75 Véase la nota 35.

76 La nobleza altomedieval gallega. La familia Froilaz-Traba, p. 62. 
cializa la nueva situación confirmando y definiendo los límites jurisdiccionales de monasterio cisterciense de Sobrado con el consentimiento de los hermanos Traba (la carta se hace con el "consilio et uoluntate comites domni Fernandi et domni Ueremundi Petri"), que (con) firman el privilegio al final ${ }^{77}$. En 1183, Fernando II ratifica una decisión anterior de Fernando Pérez de Traba de traspasar la jurisdicción de Sobrado -cuyo patronazgo le pertenecía desde 1118- a la Iglesia de Santiago, añadiendo los tributos del rey y el monasterio de $\mathrm{Mezonzo}^{78}$, lo que no debió satisfacer completamente a los monjes cistercienses, en cuyos documentos y memoriales no quedó huella de este documento, que significaba el fin del control de los Traba sobre Sobrado. A partir de aquí, los condes de Traba seguirán siendo considerados reconstructores de Sobrado por los futuros recopiladores de códices e historiadores benedictinos ${ }^{79}$. Así y todo, con independencia de sus relaciones con el Monasterio, los Traba nunca incluyeron al coto de Aranga en el coto de Sobrado, ni antes ni después de su prolongado patronazgo sobre al convento, tampoco de la desaparición de los hermanos Fernando y Bermudo en paz con los monjes. Por cuestión identitaria, preservaron siempre los castillos de Traba y Aranga, con sus jurisdicciones para la casa matriz, hasta finales del siglo XII, en pleno tránsito hacia el condado Trastamara-Monterroso ${ }^{80}$, que, dos siglos después, revolucionará el reino de Galicia y la corona de Castilla, levantándose de nuevo el viejo castillo de Aranga, para dolor de cabeza del monasterio de Sobrado y de los propios vecinos, que lo derrocarán en 1467 durante la revuelta irmandiña.

77 Tumbo de Sobrado, II, pp. 28-29.

78 Tumbo A de la Catedral de Santiago, Manuel LUCAS, edit., Santiago, 1998, pp. 271-272; confirma el documento Gómez González, nieto de Fernando Pérez de Traba y heredero del condado de Traba-Trastámara, cuya relación con Sobrado fue escasa, La nobleza altomedieval gallega. La familia Froilaz-Traba, pp. 158-169.

79 Véase la nota 46; juzgan positivamente a los condes tanto Mauricio Carbajo en el siglo XVIII como el autor del memorial de Sobrado (1633) guardado en el Instituto Padre Sarmiento de Santiago; la excepción es Antonio Yepes, quien escribía de los abuelos maternos de los condes de Traba que la envidia "dio traza que un caballero llamado Segeredo y su mujer Adonsinda se aficionasen a la hacienda y posesiones del convento", y consideraba a Fernando y Bermudo Peréz de Traba, usurpadores arrepentidos, citando para ello una escritura de devolución, en 1133, del patronazgo o posesión del monasterio que no consta en los Tumbos y Códices de Sobrado, Crónica General de la Orden de San Benito (1610), vol. II, Madrid, 1960, pp. 283, 284.

${ }^{80}$ Véase la nota 40. 